\title{
Who do you think they were? How family historians make sense of social position and inequality in the past
}

\author{
Wendy Bottero (University of Manchester)
}

\author{
This is the preprint version of the article that appeared in 2012 in The British Journal of \\ Sociology, 63(1): 54-74. DOI: 10.1111/j.1468-4446.2011.01393.x, ㅇ The Author 2012
}

\begin{abstract}
How do social comparisons over time shape perceptions of inequality? In thinking about subjective inequality, it is important to ask which social comparisons matter in establishing people's sense of relative social position and wider inequalities. These issues are discussed by drawing on a qualitative study of popular genealogy, which examines how people make sense of social position in the past, and explores how social change affects people's sense of social hierarchies. The gaze of family history promotes certain sorts of social comparisons, between 'then and now', and between immediate kin, which can flatten the sense of social hierarchies. However, the ability to determine social position also depends on the quality of information available, and how different practical engagements facilitate 'sideways' comparisons between contemporaries, affording different fields of vision on relative inequalities. On this evidence, when exploring subjective inequality it is necessary to examine when and how people engage in social comparison as part of everyday practical activities.
\end{abstract}

Keywords: Social comparison; social position; family history; subjective inequality; social hierarchy; social class; social classification.

\section{Introduction}

Genealogy as a practice traces ancestral links, but in doing so family historians are often trying to reconstruct the lives of ancestors. How does social position feature in these reconstructions? The boom in amateur genealogy has attracted researchers interested in 'sociobiographical memory' (Zerubavel 1995: 290) who examine how family history anchors and locates self-identity (as in the BBC programme 'Who do you think you are?') (Erben 1991; Kramer 2011a, b). From this angle, genealogy is used to explore 'cultures of relatedness' and notions of cultural and biological 'belonging' (Edwards 2005; Strathern 1995; Carsten 2000; Nash 2002, 2008; Tyler 2005). But family history also raises question about the present in the past, and the ways in which family historians anchor and locate their ancestors. So we can also ask 'Who do you think they were?' and explore family history as an exercise in practical social classification. This study ${ }^{1}$ examines how family historians make sense of the hierarchical social position of their ancestors, as part of an inquiry into how change over time affects social comparison and perceptions of inequality.

A relational concept, 'inequality' raises inherent questions of social comparison and 'necessarily invites us to examine the advantages of different groups or different individuals and to assess these advantages relative to one another' (Marshall and Swift 1996: 376). To establish someone's social position we need some sense of their standing relative to others, the question is which comparisons matter for our sense of social hierarchies and people's place within them. The information contained in popular genealogy is the domain of academic social mobility analysis, and data from family historians has been used in studies of historical social reproduction (Prandy and Bottero 1998, 2000a, b; Bottero and Prandy 2001); whilst the 'case family history method' has generated family stories to 
investigate 'family transmission' (Bertaux and Delacroix 2000; Thompson 2005). Less attention, however, has been paid to the significance of social hierarchy or social mobility for family historians themselves. Yet within a few generations, the linked lives in family trees bear witness to major social transformations, and on a scale which raises questions about how people make sense of inequalities in the face of such widespread change.

In this paper, the practices of family historians are examined to explore how questions of long-term change affect people's sense of historical social position and so their awareness of relative inequalities in the face of that change. Following a brief overview of debates on social location and social comparison, and the problems of researching subjective inequalities, the paper considers how family historians engage with such issues. As we shall see, when family historians discuss social position, they can make short-term temporal comparisons (over ancestors' lives, and from one generation to the next); lateral comparisons to ancestors' contemporaries (to peers in the tree or to non-kin); but also longer-term temporal comparisons (between 'then' and 'now'). But many family historians found it harder to make comparisons between people in the past, as against more straightforward comparisons between 'then' and 'now'. They also often had restricted information on ancestors' contemporaries, making location within social hierarchies harder to establish.

Although family history entails laborious, methodical research about the past - sifting and connecting archival evidence, sending off for copies, noting and recording evidence - varying ways of engaging in family history promote different 'fields of vision'. Family historians with a more developed interest in local history approached their evidence differently, and these framing concerns affected how they classified and compared. A sense of the relative social position of ancestors depended upon on the social comparisons made, but such comparisons varied significantly depending upon the practical activities of family historians. Depending on whether or not family historians prioritised kin over non-kin, or direct ancestors over indirect ones, the practical tasks of family history set limits on what historical information was relevant and interesting and - by restricting the social comparisons made between historical peers - affected the practical social classifications, and sense of inequality, which emerged from such activities. One broader implication of this is for our understanding of the relative visibility and salience of inequality. It is argued here that we must explore the practical nature of social comparison processes to examine how a subjective sense of inequality emerges out of the routine activities of when, why and how people compare.

\section{Comparison and relative social position}

How does long-term change affect people's sense of social hierarchies? To establish their own position, people often compare with those who are proximate (neighbours, friends etc.) and socially similar to themselves (Runciman 1966). But people can also compare to themselves at earlier points in time, or to earlier generations (Rose 2006). Because of rising affluence, people making temporal comparisons often see an improvement in social circumstances, personally and more generally (Pahl, Rose and Spencer 2007: 9). Most people's lives are, materially at least, better than their parents or grandparents; and even in their own lifetimes, lifestyle changes for the working class means they 'have in consumption terms been upwardly mobile, "even while we're standing still"' (Payne 1992: 220). Of course, if most people are better-off, the relative inequalities between them may remain unchanged. But how well are persisting relative inequalities (in access to education, the labour market, material possessions and income) understood, and do they matter to people? Rose suggests 'it is absolute mobility that people witness in their everyday lives' (2006: 5); and for some analysts "what matters is precisely that there is now "more room at the top", with class analysis - and its focus on persisting relative inequalities - criticized for assuming that "if everybody has gained, 
nothing really has changed' (Saunders 1995: 25). Such questions remain speculative, however, with more research on objective mobility patterns than on people's subjective understanding of social trajectories (Savage 1997; Kelley and Kelley 2009).

Family history offers a way to explore these issues, allowing us to conduct two related tasks: to examine the processes of social comparison by which hierarchical social position is determined; and to explore how social change itself affects people's sense of relative position and inequality. The rising popularity of amateur genealogy in countries like Britain, Ireland, Australia and America, and the increasing accessibility of online genealogical sources, has generated a mass engagement with archival historical research. Researching their family trees, family historians uncover details of a potentially large set of ancestors (several hundred) over a long passage of time (most trees are traced back to the 1780s). In the UK, using the census, civil and parish registration of births, deaths and marriages, and a range of other archives (trade directories, wills, land registries, court and military records, newspapers), family historians uncover information on where their ancestors lived, who they lived with, and details of their geographical movement and major life-course events, sometimes literally - from cradle to grave. Such research routinely uncovers ancestors' occupations and (for some) property and wealth. Over such a sweep of time, most family trees will show evidence of increasing material affluence, and some the absolute social mobility that widening labour market and educational opportunities have supported. How do family historians engage with such issues?

More particularly, what sense do family historians have of their ancestors' social location, and what sorts of social comparison form these determinations? What contemporary frames are deployed in envisioning inequality in the past? Notions of 'social position' are, after all, complex and multifaceted. Respondents asked to think about current 'class' issues can interpret the concept in at least 14 different ways (including lifestyle and housing; aspirations and education; aristocracy and the upper class; superiority and deference; money; job types; inequality; the class system) (Payne and Grew 2005: 903, Atkinson 2010: 165-6). Similarly, it is argued that it is not occupation but rather 'possessions, place of residence and overall lifestyle [which] provides the basis of peoples' images of themselves in relation to others' (Pahl, Rose and Spencer 2007: 17). This quality of information is unavailable for ancestors 'found' in the archive however. To form a sense of their lives family historians must painstakingly collect and interpret the fragmentary information that survives (and can be traced) in archives. Not only is less information available, long-term social change also potentially destabilises the meaning of those key markers (occupation or material possessions) which can be found.

Table 1 shows the occupational titles collected in a single family tree. Even knowing what certain jobs entailed, there is still a problem of determining their shifting social meaning, and establishing their place within historical hierarchies. In a period when over three-quarters of the population worked in manual occupations, the relative (dis)advantage of jobs is harder to establish (Bottero 2005). Similar issues arise in relation to establishing relative deprivation in conditions of widespread material scarcity. Challenging for social historians, these are thorny questions for amateur family historians, whose interests may centre more on genealogy than social history. In what follows, I look at how family historians deal with such issues: exploring the process by which they make determinations of social position, and examining the sorts of archival information and social comparisons they draw upon, as an exercise in everyday classification. 


\begin{tabular}{|l|l|l|}
\hline \multicolumn{2}{|c|}{ Table 1: Occupational and status titles from a single family tree } \\
\hline $\begin{array}{l}\text { aglab } \\
\text { allopath }\end{array}$ baker & female sick nurse & publican \\
blacksmith & french polisher & quarryman \\
book-keeper & foot soldier (private) & picture frame maker \\
boot mender & gentleman & rope maker \\
butcher & grocer & servant on a farm \\
calico printer & handloom weaver & ship's mate \\
clerk & hatter & shoemaker \\
collier & horse slaughterer & silk weaver \\
cotton operative & inspector of postmen & stay maker \\
cotton mill grinder & kitchen range fitter & stevedore \\
cotton weaver & labourer & stone getter \\
distiller & mill engineer & tailor \\
dressmaker & milliner & warehouseman \\
engine man & nurse & warper \\
excise man & parish constable & whitesmith \\
farmer & plantation overseer & workhouse attendant of male \\
& power loom weaver & imbeciles \\
\hline
\end{tabular}

\section{Let's talk about social position}

21 family historians were interviewed in an in-depth qualitative interview study based in Northern England $^{2}$. Participants were recruited through the leafleting of libraries and Family Record Centres, news-group and message-board adverts to websites of Family and Local History Societies, and by snowball sampling. The aim was to construct a sample of people engaging in family history in a range of ways (members of history groups as well those pursuing solitary web-based research). The achieved sample is not representative of any larger population, and is predominantly 'middle class', white, older and well-educated in its characteristics ${ }^{3}$. It is used here in an illustrative fashion, exploring a range of ways in which issues of social comparison and hierarchical social position emerge in family history research.

How should we research such issues? 'Inequality' raises questions about the relative worth of individuals, which can make it hard to speak about - and hard to research. Although people may readily recognize inequalities of social position, acknowledging such inequalities is more difficult, with such acknowledgment often seen as a problematic moral evaluation, with unequal social position equated with unequal personal worth. People can experience discomfort when asked directly about their class position, and shrink from being asked to 'judge' others, or may adopt a 'defensive' attitude to class labels, or prefer to speak of their own 'ordinariness' (Sayer 2005; Skeggs 1997; Savage 2000; Savage, Bagnall and Longhurst 2001). Because of concerns about stimulated responses to direct questioning, studies of class identities have focused on how such issues emerge 'spontaneously' (Devine 2004: 200). But others query whether 'spontaneous' accounts are 'automatically a better guide' since 'Silence on a topic does not mean it is not salient (or conversely that non-silence necessarily indicates salience)' (Payne and Grew 2005: 906). If views about 'class' emerge in a 'confused way' this may be because interviewees are being asked 'to handle a genuinely multi-faceted concept at short notice', and the fuzziness of 'class' makes it 'possible to talk about class without ever mentioning the "c-word"', whilst conversely, 'the idea of class may be indirectly 
and inadvertently introduced' by questions which 'steer respondents towards quasi-class frames of reference' (Payne and Grew 2005: 903, 902, 905).

Long-term historical change often serves to defamiliarize the familiar, so family historians tracing their genealogies can struggle to determine the social position of their ancestors but, in so doing, can also make explicit processes of everyday social classification which are more normally tacit. My approach was designed to explore what sorts of stories emerged 'spontaneously' in accounts of family history research, and whether and how inequality and social position featured in them. I was also interested in how people's stories related to their broader collection of documents, and whether other ways of framing and 'storying' the information might emerge. During a 3-4 hour semistructured interview, participants were asked how they had researched their family history, and about the stories that had emerged, using 'family tree elicitation', an extension of photo elicitation (Hirsch 1997). The interview chiefly explored respondents' family trees and the documents relating to them, with discussion guided by the information my respondents chose to highlight. But I also asked to look at ancestors for whom there was more archival evidence, with an interest in the range of information (about occupation etc) that people might have collected as 'hinterland' to the stories they were framing. Lastly, respondents were asked directly if they had a sense of the 'sort of life' their ancestor led, and - if this had not already emerged - if they had a sense of their ancestor's 'social position'.

The next sections examine the different ways in which a sample of family historians made sense of social position in the past. It should be noted, however, that such questions were not generally the focus of respondents' 'spontaneous' stories about their ancestors, though information germane to this had generally been recorded. Accounts were strongly 'storied', often with a 'polished' feel, and some historians had written up narratives of their ancestors. But, I shall argue, only certain sorts of archival information made for 'good' stories.

\section{Family histories}

The scraps of evidence that survive about ancestors' lives usually include information about occupation. Yet some people struggled to remember the occupations of ancestors, and had to search through files to retrieve the information. Others had occupational information more readily to hand, but questions of occupation or social position were generally collateral information in the stories on which my sample focused.

You're never looking for the boring stuff - you get a lot of farmers who have the same name... But you're really looking for stories of people that did something different. (Sally $\left.{ }^{4}\right)$

'Interesting' stories might be about ancestors whose lives crossed paths with 'great moments in history': the marine who served at Trafalgar; the bride whose wedding was attended by F. Scott Fitzgerald; the child body-snatched by resurrectionists (though not, as family legend had it, by Burke and Hare ${ }^{5}$ ). Other records provided intriguing cameos, with respondents keen to show me vivid glimpses of past lives: in the newspaper report of the shipwrecked mariner who died ' the greater portion of his body destroyed by crows'; the schoolboy report of a 'plodding scholar' who 'does good work so far as his ability goes'; or the soldier's army record listing 13 hospital visits, 11 for gonorrhoea. For most, however, this level of detail was unavailable, and to form a sense of their lives family historians had to read between the lines: 
It's been a very involved story of possible bigamy, abandoned children, lying on birth certificates, you know, a really complex story of several children born out of wedlock and not married until afterwards, but sort of saying on the birth certificate that you were. (Pauline ${ }^{6}$ )

By the nature of family history research (which uncovers geographical movement, births and marriages, household residence, and encounters with authority) ancestors who stand out tend to be those whose lives were picaresque or peripatetic, or both. Certain ancestors - 'mad, bad or dangerous to know' - had lives of incident, documented through prisons, lunatic asylums and so on. More routinely, were ancestors whose apparently erratic movements - geographic and domestic begged explanation, and suggested 'hidden histories' of sexual lives, and the pressures and hardships of life in the past.

He stayed in Kent and married and she brought the three surviving children plus one that she was carrying back to Derby. But it looks like she had nowhere else to go, because her father was in the workhouse ... And then the children were looked after by the workhouse afterwards. (James ${ }^{7}$ )

Many accounts focused on the shifts and migrations associated with industrialization or colonisztion, and precarious working and family lives. Such stories often conveyed a sense of 'traditional' industrial or occupational communities, of the type associated with older narratives of working class identity (Savage 2000):

his father was killed when he was a baby in an ironstone mining accident, I think something fell on him and there's a lot of that ... people being killed, in mining accidents and you know, there's a lot of babies dying $\left(\mathrm{Carol}^{8}\right)$.

Typical of working class, northern, little market town, full of cotton mills and coal mines--just, excuse the pun, run of the mill ... Communities were far superior back then [...] they were better people, weren't they? (Joe $\left.{ }^{9}\right)$

Less common, were 'status stories' in which markers of social position were highlighted as an 'interesting' feature of an ancestor's life. These emerged where there seemed to a significant status or class gap between people intimately linked in the genealogy: a gap which begged explanation generally in what might be termed 'upstairs-downstairs' stories. Carol had pieced together the story of a female ancestor, housekeeper to an undertaker, who had four illegitimate children by him:

she had children illegitimately, didn't name a father ... Joseph was the father, but that relationship couldn't be acknowledged because she was a working class servant girl, her father had been a miner... and clearly he was more of the business class ... I think he had some kind of social standing. That as a funeral director probably, it just wasn't ... you know, impregnating your housekeeper...over and over again! (Carol)

Jean had identified a story of status discrepancy in the 'mystery' of a 'nurse to male lunatics' later found in America as a 'physician'. Not a straightforward case of upward mobility, this was a juicier story of an imposter:

I couldn't quite get my head around this, because I thought, his father worked in a cotton mill, where's this coming from? And I thought ... this was a mid-Atlantic qualification. [So you think he was a fraud?] Oh yes, I'm sure he was ... I call him the snake oil man. And he christens his son Montclair, where's he coming from with that lot? Oh, there's no end to his goings on. $\left(\right.$ Jean $^{10}$ ) 
Other stories focused on those who had fallen on hard times:

they were reasonably $\mathrm{OK}$ and then he died. And her mother, she had another child just before her husband died, and her and the younger child go off to live with someone else as a lodger.

But the eldest girl gets put into this care. (Sally)

However, such stories of status gaps or falls were comparatively rare, perhaps surprisingly so given that accounts of hardship and precarious lives were commonplace. Because it often appeared hard for people to determine the relative position of ancestors, status stories emerged when a social comparison identified a marked status discrepancy: one that was so clear-cut and significant that there could be no doubt of a gap or fall. However, the most clear-cut and unambiguous comparison to make was not laterally (between ancestors or their contemporaries) but temporally - between then and now. It was temporal social comparisons which were most readily drawn upon.

\section{Looking back at change}

The framing of family history is about tracing ancestors back in time: in doing so the nature of lives in the past is thrown into starkest relief by the comparison with today. In response to questions about the sorts of lives ancestors had led, a common response was to make long-range temporal rather than lateral comparisons: indicating how hard people's lives were in the past (and the much greater resilience - and moral worth - required to endure them) compared to now:

I think it would be hard physical labour and - I suppose the thing you think about, is that they wouldn't have had our mod cons; that they would have lived in cold, wet, damp, draughty houses probably with not enough to eat. $\left(\operatorname{Dan}^{11}\right)$

'Then and now' comparisons are part of a readily available and widely used narrative of social change as material progress, and are perhaps the most obvious conclusion to draw about life in the past, particularly in tracing back family trees whose point of departure is ego. Such comparisons are not the only way of framing past lives, however:

'Overlooker in a cotton mill' - well if you read something like, I can't think of the man's name but he worked at a mill in Clitheroe and wrote this wonderful book where he keeps a diary...if you read that you think well yes, they had the same kind of position in a mill ... They're going to have pretty much the same sort of lifestyle. (Jean)

But Jean's sideways glance between historical peers was rarer than 'then and now' comparisons of lives. In engaging in family history, after all, the gaze is directed towards looking back. But almost everyone lived a harder life in the nineteenth century compared to now. So 'then and now' comparisons tend to flatten the hierarchical distinctions between people in the past. They can also compress historical change. Strikingly, when respondents were asked about the changes they saw in their family trees, three-quarters identified 'real' change (normally material improvements, but also greater educational and occupational opportunities) as having occurred very recently, in the very last generations of their tree - within the lives of parents or grandparents - or, for older respondents, since childhood:

I think people probably expected to live their lives exactly as their parents did ... My dad's 90 . He's lived through an incredible time. He would have been born, thinking he'd live his life like his granddad and now he sits there with a phone and a TV and used to drive around--it's just an incredible life, isn't it? $\left(\operatorname{Ken}^{\mathbf{1 2}}\right.$.) 
Family changes were tied to societal shifts (the welfare state, expansions in education etc.), but given the sample's wide age range, their timing of 'real' change also varied widely (the 1890s, 1920s, $1950 \mathrm{~s}, 1960 \mathrm{~s})$. Of course, family history frames historical time as generations within a lineage (Lambert 1996). The point here is that the timing of significant change was linked to familial comparisons to generations located within living memory. Partly we may see this as a question of narrative ease - drawing upon readily available family narratives comparing the lives of parents and children. However, many family historians also saw comparatively little change in the hundred or so years before, emphasizing the continuity and similarities between the generations of earlier, more 'historical' forebears:

I have a sense of remarkable consistency until my mum and dad's generation really (Anna $\left.{ }^{13}\right)$.

I've not noticed any social change. I think everybody seems to just tick along. I haven't noticed anything where it's they become - they've worked really well and they've built six businesses and then they drop and - I've not noticed anything like that. $\left(\mathrm{Jacky}^{14}\right)$

Jacky's comment resists a social mobility discourse in relation to more distant forebears, which may be a rejection of the morally charged nature of such attributions. It may also be that the complex fates of so many ancestors resisted any simple linear framing. But Jacky seemed more comfortable talking about upward shifts (through education) for the most recent generations of her family, including herself. Family history is often framed in democratic terms - the recovery of those forgotten by history - and accounts of ancestors sometimes featured 'moral work' in relation to them. Respondents were frequently careful to avoid 'judging' their ancestors (emphasising that worse times did not mean worse people), but such statements were often embedded in accounts of recent social mobility:

We've gone from perfectly respectable coalminers to a PhD in 150 years ... Because I don't want to give you the impression that I'm in any way saying that because my son has a good degree and my daughter has a $\mathrm{PhD}$ that I therefore think they're better people than the people who worked damn hard hewing coal. (David ${ }^{15}$ )

More generally, people spoke more readily of change as social mobility in autobiographical terms, in narratives of their own trajectories out of working-class backgrounds or, if they did not see mobility for themselves, in terms of improved material circumstances or better opportunities for children or grandchildren. Invidious distinction is perhaps less morally troubling if applied autobiographically, and when the comparison includes a historical 'past' with such a low baseline.

It was not just that recent changes appeared so much more marked than what had gone before, but also that respondents were more confident in making judgements about the social position of recent generations compared to more 'historical' forebears. With a more detailed sense of the education, housing and lifestyle of parents, grandparents and children, family historians were able to balance up different elements in a more complex sense of social location. And the 'then and now' framing of discussions of recent absolute mobility or affluence were often qualified by sideways comparisons, and a sense that family change was relative and depended on changing times.

I think it's relative to the timing--I think that everybody's sort of moved up the social scale. So I think the social scale overall has moved up. $\left(\right.$ Jerry $^{16}$ )

A focus on the absolute scale of recent change need not eclipse a sense of the relative nature of those changes, and lateral comparisons occurred alongside temporal ones. However, this notion of 
'a rising tide raising all ships' was complex, and could be employed in different ways; to assert the persistence of disadvantage within change, or to suggest the 'ordinariness' of upward trajectories:

they didn't have any money, and they lived in cramped conditions, clearly we're not like that now. So relatively better off. Yeah, but still I think there are parts of the family that would still struggle, still earning a weekly wage rather than a monthly wage and all those sorts of things. So in that sense, still relatively poor. (Anna)

That whole sort of expansion of education took me to the polytechnic ... Whereas the generation before I probably would have been in clerical work and the generation before that I might have been doing manual work so I suppose I'm being very confused here about what I'm saying, I'm not convinced completely that the family is ever upward mobile. (James)

However, as I argue next, the further back in time family historians went, the harder it was for them to make such complex distinctions of relative position.

\section{Placing people in the past - fields of vision}

In trying to place ancestors in social hierarchies, family historians are not just engaged in a potentially morally charged exercise, they also face a complex task of classification, in disentangling and weighing up multi-faceted aspects of 'social position' (Payne and Grew 2005), and in trying to apply such criteria to the foreign country of the past. In studies of contemporary subjective inequalities, people tend to place themselves in the middle of social hierarchies, part of the middle mass of 'ordinary, hardworking families' (Pahl, Rose and Spencer 2007; Evans and Kelley 2004; Savage, Bagnall and Longhurst 2001). The same feature emerges when family historians discuss their ancestors' place in social hierarchies, with similar qualifications, claims to 'ordinariness' and 'muddle in the middle':

They lived in a--, I suppose, a middle class area of Birmingham at that time, although it was probably a working-class area ... It's hard to tell really ... It was in the industrial area where people went to work, so I would have assumed that they wouldn't have been poor people, they would have had an income coming in, but then they wouldn't have been rich either. So, I don't know whether you'd call them middle class or working class, somewhere between the two probably (Jerry).

Following the literature on class identities, we might see such qualifications as reflecting ambivalence about class labels or a moral concern about implying that 'higher' or 'lower' position also means 'better' or 'worse' people. However, such qualifications can also be seen in a rather more straightforward light, as a reflection of the nuance and complexity of the classification task. To gauge the position of ancestors, family historians must engage in a genuinely difficult exercise of attribution and classification, one further complicated by problems of shifting historical context. All forms of classification are prone to qualification and 'splitting' into finer distinctions, in order to make schematic labels better fit people's sense of a more complex reality (Zerubavel 1991). Cannadine (1998) shows exactly these processes in the history of 'class' discourses, categories qualified by finer distinctions. For family historians, there is also the issue of what information is available, and the comparisons that can be drawn on in order to make sense of that information.

With limited archive evidence, it often appeared hard for family historians to make sense of information on social position, unless that information was very clear-cut. As in accounts of 
contemporary inequalities, family historians sought to establish markers of the 'top' and 'bottom' of the hierarchy in order to place ancestors:

people dying in workhouses, that sort strikes with poverty, don't it? And early deaths, and infant mortality and so on. (Ken)

They might be a cut above because they were working. They weren't paupers. (Leonard ${ }^{17}$ )

Indicators of social position referred to included occupation, residence (neighbourhoods, household size and occupancy) as well as demographic information. However there was caution about how to interpret such evidence. Elite ancestors leave more richly documented lives, giving a clearer sense of their social position, but for the rest questions of social position are trickier. Even with evidence of assets, unless ancestors were clearly members of an elite, respondents were cautious about how well they were doing, qualified in the conclusions they drew about social position, and doubtful over whether they were 'out of the ordinary'. An ancestor might be a shopkeeper, a farmer, or a publican, but it could have been a poor sort of business, so they might not have been doing that well:

People were more entrepreneurial in those days anyway weren't they? So they were much more kind of, you know, people starting businesses but it didn't mean necessarily that they were successful or had a lot of money or anything. (Carol)

One apparent marker of a 'good' business, or a sizeable property, was if it had been 'handed down', but respondents were more likely to express scepticism about an ancestor's social position because property was not inherited:

[So you've got some property on both sides of the family?] Well, it is a - it is a little - the thing is it's sort of - it sort of went and disappeared. I don't think there's any of it left in the family.

(Dan)

This intergenerational framing of property questions perhaps led to an exaggerated caution about assets. Certainly such accounts were rarely framed as stories of downward social mobility, but rather taken as evidence that the property (and social position) had probably not been that significant. Similar issues arose at the other end of the spectrum. Household over-crowding, infant mortality, or 'bad' neighbourhoods were taken as signs of poverty, but with indicators of material deprivation there was often a question whether ancestors were poor for the times.

They lived in places which I imagine we would regard as hovels today. Whether they felt themselves hard up or not I don't know, and clearly they would be by our present standard but ... housing was terrible, crowded slums, infant mortality and all the rest of it, but that was what they knew. $\left(\right.$ Eric $\left.^{18}\right)$

Workhouses separated family members, so workhouse residence was often taken as a marker of the worst destitution, even for the times. Conversely, no evidence of workhouse attendance was a sign of 'ordinary' working class lives.

They're not rich and they're not poor, but I think they've all managed and they've done - there doesn't seem to be anybody who has kind of been in workhouses at the age of eight or whatever. (Jacky) 
However, some noted that any distinction between the very poorest and other workers was a precarious one, leading to caution about the workhouse as a marker; whilst others made finer contextual distinctions between charity recipients:

an accident at work and the whole family was affected, and perhaps the family was split up. You know, some had to go in the workhouse or some were farmed out to other families to look after the children. So it went from sort of just being above the basic living poverty line to slipping below it. (Pauline).

A lot of the ones who worked in the cotton trade ended up on parish relief, in the end, but they never seem to have been in the sort of straits where they ended up in the work house or anything. One or two of them died in the workhouse infirmary but they, then you did in those days cause there was nowhere else to go. (Jean)

Family historians drew on varying levels of social historical detail to help make their determinations of social position. Greater information gave more social context, which often allowed finer distinctions between historical contemporaries and more confident assertions of relative social position:

a spindle and fly maker was quite a well-paid job in the cotton industry. I think, just from research I've done, it was a sort of a specialist job. (Pauline)

it's designated as the poorest area ... The description by William Booth of a neighbourhood, where the $\mathrm{H}^{*} \mathrm{~s}$ ' lived - 'fourth rate prostitutes' - that was a cesspit. I found details of what it was like to live in that part of London by going online and looking up the local history society. (David)

But in thinking about family history as a practical engagement with archives, we must think about how and why family historians come to know things about their ancestors, and how this affects their accounts and classifications. Atkinson argues that uncertainty in practical classification emerges when participants in interviews are 'forced to become quasi-sociologists' since 'Almost scholastic reflection on mundane reality is...not a familiar or effortless task' (2010: 174). But Atkinson notes too that we must ask how classifications emerge from different kinds of practical engagements. We might expect questions of cultural capital to have affected people's research and accounts, and within the sample there was a major difference in approach according to whether people mainly framed their research in terms of family history, or included a stronger local or social history angle. This division did not straightforwardly coincide with the cultural or economic capital of respondents, however, as the 'family historians' were the largest group and included the most educated of the sample, whilst the local historians included one of the working-class respondents. The small size, and restricted class coverage of the study (with few working-class respondents) limit any conclusions that can be drawn from this. But it is worth noting that for all respondents, family history was a 'scholarly' leisure pursuit entailing laborious and time-consuming engagement with archives, verification across multiple sources, and navigation around dead-ends and false leads.

Family history is, in one sense, itself a 'quasi-sociological' exercise (Lambert 1996). It operates as a set of practices and discourses of expertise, and accounts of the research process are prominent (Edwards 2009). The sample dwelt on their trawls through archives to piece together accurate evidence, and their problems in correctly interpreting it. The research process and archive sources were an integral component of stories about ancestors, and respondents' caution and qualifications about the social position of ancestors should be seen in this light. However, differences in how and why people conducted family history research provided distinctive fields of vision on the past, with 
different social comparisons and classifications emerging from varying practical engagements with archival evidence. These engagements had different framing consequences: setting limits on whom and what was of interest in the research.

All family historians have a broad interest in the past, but with significant differences in the extent to which they pursue an interest in local or social history, and therefore are interested in people in the past who are not their ancestors. A distinction is sometimes drawn between family history and genealogy (with the latter seen as a narrower exercise of establishing kinship links) (Erben 1991), but all the participants in this study shared a concern with putting ancestors into historical context (cf. Lambert 1996). But a continuum ranged, from those drawing upon general historical narratives of the circumstances (industrialization, wars etc.) in which ancestors had been caught up, to those pursuing much more specific and detailed additional research into local industries, neighbourhoods, and institutions. Some of this latter information is thrown up incidentally in the process of tracing ancestors, but there are significant differences in the extent to which family historians focus on this contextual information and pursue it in its own right. The framing of family history, and the different techniques by which it is conducted, set limits of interest which affect the lateral social comparisons that are made.

James, for example, conducted local history and family history research as quite separate hobbies (his local history research was of an area unconnected to his ancestors). His pursuit of local history included the painstaking collection of census, rate-book, account and register information, for everyone he could trace in his neighbourhood in the nineteenth century:

I know how much they were paying on rent. I know how much potentially they were paying for things like repairing shoes and stuff like that ... I can go to sleep at night knowing who's walking up and down and living on the road. (James)

For James, a census return was not a way of tracking his family every 10 years, but rather a window on the activities going on in an area. This local history angle promoted a 'sideways' look at historical contemporaries, and facilitated wider ranging social comparisons. For example, he looked at Parliamentary Reports on wages, to make sense of local pay, allowing a more detailed identification of social hierarchies of the time:

handloom weavers by the 1840 s are being paid very very little compared to their opposite numbers in the factories. So in terms of other incomes, for instance, a labourer was getting about 18 shillings a week. A policeman was being paid about a pound and textile workers were probably getting, I think from memory now about the same as a labourer maybe a bit more. (James)

This perhaps is closer to an abstract 'scholastic' approach to archival historical research. But rather than simply distinguish it from the more 'practical' engagements of family history, we should recognise that both local history and family history are practical engagements with archives as a leisure pursuit, but ones with different framing concerns that affect the information - and social classifications - that emerge.

Edwards' ethnographic study of a local family history group in the post-industrial North-West found a 'flourishing interest in social history and ... the workings of social class' in the production of a history that 'marries place, past and person' (2009: 17). Such groups provide resources for those tracing ancestors in a particular area, but for 'core' members their activities (volunteer work transcribing records for the area, talks on local people, industries etc.) are also a leisure pursuit in which local history information is an end in itself. Joe, for example, had started pursuing his family 
history after participating in his local heritage group's efforts to preserve his town's industrial landmarks:

I got into this $\mathrm{J}^{*}$ Mill thing, and walking around, I thought, oh my family worked here, a lot of people worked at $\mathrm{J}^{*}$, and it pretty much killed them, with all the dust and that-- I might as well start my family tree here. (Joe)

Such connections between place and past can provide a rich sense of ancestors' locations within a wider milieu, and a stronger 'sideways' awareness of historical social distinctions. But in my sample the active members of such groups were particular in their approach. Others were researching their ancestors online, with little connection to organized groups. If ancestors had stayed put, or the family historian had focused on a 'local' lineage, then family and local history coincided. For many, however, family history and local history did not straightforwardly connect. The migrations of ancestors and dispersal of different lineages meant there were many local histories to take into account. Information about local context was thrown up in passing, but the extra time and resources required to 'look sideways' at historical contemporaries or milieu was often a distraction from the central task: tracing direct ancestors back through time.

One way of looking sideways at historical contemporaries without conducting additional local historical research is to look at the neighbours on ancestors' census records. Website archives routinely display adjacent households in the census (though additional payment may be required to see more), and genealogical guides advise family historians to look at neighbours, to see if a family member can be found further down the street. But neighbours were not necessarily of interest in themselves, with the sample infrequently noting their details, and rarely remarking upon them. Sally was an exception both in taking a direct interest in neighbours and in using them to draw conclusions about ancestors' relative social position:

the occupation of some of the people in the terrace you can see they're kind of reasonably wealthy; professor of modern languages, what he's doing in Bolton, I don't know? [Is this in the same household?] No this is in the same street but you can sort of see that it's kind of quite a middle class, quite a few of them have servants: corn miller, draper, professor in modern languages, hairdresser, butcher's master. (Sally)

More generally, it was the 'local historians' who took a direct interest in neighbours, and who drew conclusions about social hierarchies from them, because lateral comparisons were more central to their field of vision, which drew in non-kin as well as kin.

The focus on ancestral links in family history meant historical social comparisons were often contained within the family tree. Some respondents spoke of their disappointment at having to exclude namesakes with 'good stories', because they were not 'family' after all. But even within this kinship frame, direct ancestors took priority over great-great-uncles and aunts, or cousins at a remove. As Nash (2003: 199, see also Edwards and Strathern 2000) notes, the 'potentially limitless nature of the family tree' requires family historians to focus selectively on who is really 'family', however such flexible selections are significant for the social comparison process. At the end of the interviews, I probed on social position by asking whether people saw contrasts within their family tree: if siblings had different fates; if some parts of the family were doing better than others; if there were changes (falling on hard times etc.) over an ancestor's lifetime or from one generation to the next. These sorts of issues can emerge in everyday accounts of family relations, and I was interested to see if they featured in relation to the 'archival' family. However, such comparisons within the tree were not readily to hand, and many respondents struggled with the questions. Partly this is related to the problem of identifying 'clear-cut' contrasts in ancestors' social position over time, but the focus 
on 'direct' ancestors also often restricted lateral 'within tree' comparisons. Within the sample, few had spent much time researching 'sideways' in the tree, or following the fates of a direct ancestors' siblings:

it seemed less interesting really, and also, how do you do it? I've got to get birth certificates for all of these people and, you know ... they've got huge families, 12, 13 children in some of the families and so I think, once I'm retired or something, I might do that, but I was just more interested in the main branches really and the main people. (Anna)

It is easier and more systematic to track direct ancestors back in time, and where siblings had serendipitously cropped up as adults in the subsequent records of direct ancestors (sharing lodgings, witnessing certificates etc.) family historians were interested and took note of their situations. But indirect ancestors were often of only incidental interest, and so sideways comparisons to historical contemporaries within the family tree were also restricted.

\section{Conclusion}

Family history constructs a set of relations (between now and then, people and places, between generations and within them, and between kin and non-kin). In doing so, however, it often gives priority of interest to kin over non-kin, and to direct ancestors over indirect ones, restricting the social comparisons that can be made between historical peers. Different practical engagements promote different fields of vision, in which family historians are not engaged in representing the past, but rather are conducting practices (of archival archaeology) which construct a recovered past. The experience and character of this past depends on how family historians engage in these activities, and so frame their research and information in ways which make relative inequality and hierarchical social position more - or less - visible.

The practices of family historians have been examined in relation to two questions: how processes of social comparison are used to determine historical social position; and how social change itself affects family historian's sense of relative position and inequality. Social psychological research emphasizes the ubiquitous nature of comparison: indicating we compare constantly, to make sense of the world and orient our actions; but also that the nature of our comparisons shifts, depending on our reasons for comparing and the social contexts and practices in which we are engaged (Suls and Wheeler 2000; Zagefka and Brown 2006). In reflecting on the social comparisons, and determinations of hierarchical social position, that emerge from family history, we might adopt the pragmatist maxim 'My thinking is first and last and always for the sake of my doing' (James 1983: 960). Why and how family historians acquire information on the social position of their ancestors affects the different types of social comparison, and practical classifications, which emerge from their activities.

It is sometimes suggested that social change in affluent societies masks relative inequalities, because absolute shifts in social conditions are more visible to people in their everyday lives, and temporal comparisons promote a sense that 'now' is better than 'then'. However, on the basis of this small, exploratory study, we might argue that this depends on when, how and why people compare. Certainly, the gaze of family history looking back over the long sweep of generational change produces strong 'then and now' comparisons, in narratives of increasing material prosperity and improving opportunities for all (though these changes are seen as very recent, for the family within living memory). But discussions of recent improving prospects were qualified by sideways 
comparisons to contemporaries, and by a sense that such change was relative. Temporal comparisons do not preclude a sense of relative inequalities.

For practically all the family historians, limited information and the estrangements of time made it harder to make sense of information on historical social position, and produced qualified and cautious accounts of it. For some, the archive produced information about occupations, households and neighbourhoods as an interesting by-product of the tracing and corroboration process. If prompted, this evidence was drawn upon in thinking about ancestors' relative position, but it was not to the forefront in 'spontaneous' stories about ancestors, unless it was very striking or clear-cut. For others, family history was allied to a more direct pursuit of social or local historical information on non-kin, permitting wider, more varied and more confident comparisons between historical contemporaries, which helped in determining social hierarchies. But such a 'sideways' focus was often incidental to, and sometimes a distraction from, the task of tracking ancestors.

The family historians' sense of social position in the past was gathered from their movements through family history archives, in which varying practical engagements with archival evidence facilitated different kinds of social comparison. One issue to emerge from this research is the varying visibility and salience of relative social position in everyday accounts of social life, depending on the sorts of routine social comparisons that people undertake as part of different practical activities. In thinking about subjective inequality then, it becomes important to explore further when, why and how people compare, and to examine how such comparisons are affected by social change and affluence, the nature of people's contacts and networks, and the context of different kinds of social practices.

\section{Bibliography}

Atkinson, W. 2010 Class, Individualization and Late Modernity, Basingstoke: Macmillan.

Bert.aux, D., and Delacroix, C. 2000 'Case Histories of Families and Social Processes' in P. Chamberlayne et al (eds) The Turn to Biographical Methods in Social Science, Abingdon: Routledge.

Bottero, W. 2005 'Interaction Distance and the Social Meaning of Occupations', The Sociological Review Special Issue 2(3): 56-72.

Bottero, W. and Prandy, W. 2001 'Women's Occupations and the Social Order in Nineteenth Century Britain' Sociological Research Online, 6 (2) http://www.socresonline.org.uk/6/2/bottero.html

Cannadine, D. 1998 Class in Britain, London: Yale University Press.

Carsten, J. 2000, 'Introduction' in J. Carsten (ed.) Cultures of Relatedness, Cambridge: Cambridge University Press.

Devine, F. 2004 'Talking About Class in Britain' in F. Devine and M. Waters (eds) Social Inequalities in Comparative Perspective, Oxford: Blackwell.

Edwards, J., 2005 “"Make-up”: Personhood through the Lens of Biotechnology', Ethnos 70(3) 41331. 
Edwards, J. 2009 'The Ancestor in the Machine: Family History and Genealogical Practices in the North of England', CRESC Working Paper 71, CRESC: Manchester.

Edwards, J. and Strathern, M. 2000 'Including Our Own' in J. Carsten (ed.) Cultures of Relatedness, Cambridge: Cambridge University Press.

Erben, M. 1991 'Genealogy and Sociology’, Sociology 25(2):275-92.

Evans, M. and Kelley, J. 2004 'Subjective Social Location: Data from 21 Nations', International Journal of Public Opinion Research, 16(1) 3-38.

Hirsch, M. 1997 Family Frames, London, Harvard University Press.

James, W. 1983 [1890] The Principles of Psychology, Cambridge Massachusetts: Harvard University Press.

Kramer, A-M. 2011a 'Kinship, Affinity and Connectedness: Exploring the Role of Genealogy in Personal Lives', Sociology 45(3):379-95.

Kramer, A-M. 2011b 'Mediat[is]ing Memory: History, Affect and Identity in "Who Do You Think You Are?"' European Journal of Cultural Studies 14(4): 428-45.

Kelley, S. and Kelley, C. 2009 'Subjective Social Mobility Data from 30 nations' in M. Haller, R. Jowell and T. Smith (eds) Charting the Globe: the International Social Survey Programme, 19842004, London: Routledge.

Lambert, R. 1996 'The Family Historian and Temporal Orientations Towards the Ancestral Past', Time and Society, 5(2):115-43.

Marshall, G. and Swift, A. 1996 'Merit and Mobility: a Reply to Peter Saunders', Sociology 30(2):375-86.

Nash, C. 2002 'Genealogical Identities’, Environment and Planning D, 20(1):27-52.

Nash, C. 2003 “"They're Family!” Cultural Geographies of Relatedness in Popular Genealogy’ in S. Ahmed, A. Fortier and M. Sheller (eds) Uprootings/Regroundings, Oxford: Berg.

Nash, C. 2008 Of Irish Descent: Origin Stories, Genealogy, and The Politics of Belonging, Syracuse University Press.

Pahl, R. Rose, D. and Spencer, L. 2007 Inequality and Quiescence: A Continuing Conundrum, ISER Working Paper 2007-22. Colchester: University of Essex.

Payne, G. 1992 'Competing Views of Contemporary Social Mobility and Social Divisions' in R. Burrows and C. Marsh (eds), Consumption and Class, Basingstoke: Macmillan.

Payne, G. and Grew, C. 2005 'Unpacking “Class Ambivalence”: Some Conceptual and Methodological Issues in Accessing Class Cultures', Sociology, 39(5): 893-910.

Prandy, K. and Bottero, W. 1998 'The Use of Marriage Data to Measure the Social Order in Nineteenth-century Britain', Sociological Research Online, 3,1

http://www.socresonline.org.uk/3/1/6.html 
Prandy, K. and Bottero, W. 2000a 'Social Reproduction and Mobility in Britain and Ireland in the Nineteenth and Early Twentieth Centuries', Sociology 34(2):265-81.

Prandy, K. and Bottero, W. 2000b 'Reproduction Within and Between Generations: The Example of Nineteenth-century Britain', Historical Methods 33(1):4-15.

Rose, D. 2006 Social Comparisons and Social Order. ISER Working Paper 2006-48. Colchester: University of Essex.

Runciman, W.G. 1966 Relative Deprivation and Social Justice, London: Routledge Kegan Paul.

Saunders, P. 1995 'Might Britain be a Meritocracy?', Sociology 29(1):23-41.

Savage, M. 1997 'Social Mobility and the Survey Method: A Critical Analysis' in D. Bertaux and P. Thompson (eds) Pathways to Social Class, Oxford: Clarendon Press.

Savage, M. 2000 Class Analysis and Social Transformation, Buckingham: Open University.

Savage, M. Bagnall, G., and Longhurst, B. 2001 'Ordinary, Ambivalent and Defensive: Class Identities in the Northwest of England', Sociology 35 (4):875-92.

Sayer, A. 2005 'Class, Moral Worth and Recognition', Sociology 39(5):947-63.

Skeggs, B. 1997 Formations of Class and Gender, London: Sage.

Strathern, M. 1995 'Nostalgia and the New Genetics', in D. Battaglia (ed.) Rhetorics of SelfMaking, London:University of California Press.

Suls, J. and Wheeler, L. (eds) 2000 Handbook of Social Comparison. New York: Kluwer/Plenum.

Thompson, P. 2005 'Family Myths, Models and Denials in the Shaping of Individual Life Paths' in D. Bertaux and P. Thompson (eds) Between Generations: Family Models, Myths and Memories, $2^{\text {nd }}$ edition, Oxford: Oxford University Press.

Tyler, K. 2005 'The Genealogical Imagination: The Inheritance of Interracial Identities', Sociological Review 53(3): 476-94.

Zagefka, H. and Brown, R. 2006 'Predicting Comparison Choices in Intergroup Settings: A New Look' in S. Guimond (ed.) Social Comparison and Psychology, Cambridge: Cambridge University Press.

Zerubavel, E. 1991 The Fine Line: Making Distinctions in Everyday Life, London: University Of Chicago Press.

Zerubavel, E. 1995 'Social memories: steps to a sociology of the past', Qualitative Sociology 19(3):283-99.

Notes 
${ }^{1}$ The study was funded by the ESRC Centre for Research on Socio-Cultural Change (CRESC) and the Morgan Centre for the Study of Relationships and Personal Life. The author gratefully acknowledges this invaluable assistance. I am also grateful for the very helpful comments and advice on this paper offered by Brian Heaphy, Katherine Davies and the editors and referees of the BJS.

${ }^{2}$ The sample included historians based in the North England researching ancestors from elsewhere (including outside the UK), and historians researching ancestors from northern England who themselves lived elsewhere. All, bar one, resided in the UK.

${ }^{3}$ The sample comprised 13 men and 8 women. All bar one were 'white'. Their ages ranged from 25 to 79 , with a mean age of 57. Of the 21, 4 were in NS-SEC 'routine or manual' class occupations', 1 in an 'intermediate class' occupation and 16 were in 'managerial or professional' class occupations, with these latter considerably higher in cultural rather than economic capital, with a preponderance of workers in education.

${ }^{4}$ Administrative assistant, 31

${ }^{5}$ Before 1832 in Britain, restrictions on the legal supply of cadavers resulted in medical schools (illegally) relying on 'resurrectionists' to disinter newly buried corpses for dissection. William Burke and William Hare were notorious serial killers who short-cut this supply and demand chain, providing cadavers through murder.

${ }^{6}$ Housewife, formerly personnel officer, 51

${ }^{7}$ Retired teacher, 60

${ }^{8}$ University researcher, 42

${ }^{9}$ Labourer, 25

${ }^{10}$ Retired registrar, 76

${ }^{11}$ Retired teacher, 54

${ }^{12}$ Teacher, 54

${ }^{13}$ University professor, 49

${ }^{14}$ Enterprise co-ordinator, 29

${ }^{15}$ Retired teacher, 65

${ }^{16}$ Business development manager, 59

${ }^{17}$ Retired mill engineer, 79

${ }^{18}$ Retired researcher, 79 